\title{
Significance of Archetypes in Literature with Reference to Literary Criticism
}

\section{Ali Ismael al-Jaf / Wasit Health Directorate}

\author{
دلالة النماذج الأصلية في الأدب بالإشارة الى النقد الأدبي \\ علي إسما عيل الجاف / دائرة صهة واسط
}

\begin{abstract}
:
The paper presents such information that can help to illustrate the meanings and functions of literary devices like archetypes in which we have seen how their importance makes ideas clear and aimed in terms of using them as tools in criticism. Motifs, symbols, images, and other tools are used to show that archetypes as things related thoroughly to human culture and elucidate the form and meaning of such psychological references to depict the standards away from genres that represent complex thoughts. Literary criticism, as shown clearly, tries to emphasize on feelings, emotions, passions, and pleasure that could be isolated from the language of truth: it is science. Archetypes are used as a system that talks about culture in relation to society and psychology; but it needs a quest in which we look for our identity and role in this universe.
\end{abstract}

Keywords: Emotions, Device, Function, Society, Culture, Literary Criticism, Archetype

\section{Introduction:}

Archetypes are new additions to the various literary devices in use such as metaphor, imagery, and symbol. In addition to, working as a literary device, it also works as a tool to bring order, as Eliot (2010: P. 86), says: "to the immense panorama of futility and anarchy which is contemporary history." It is a part of the unconscious psyche of man which projects itself into the conscious by means of "motifs", "primordial images", or "archetypes". Myth has proved to be a much more useful tool that helps to achieve more suggestiveness, and more expansion of meaning by saying so many things with so little. It is concerned with the past cultural traditions or modes of beliefs. It is also concerned with the present values, and future hopes and aspirations. We find certain motifs and images recurring in different mythologies of people widely separated in time and place and having a common meaning, eliciting comparable psychological responses and serving similar cultural functions. Such motifs and images have been called "archetypes". They are described as universal symbols.

Paul (1980), points out that critique was the essential activity of reason. Critique can focus on the abstracting aspect of understanding, as opposed to basing its judgments upon them (Marinela, 1918: P. 227). There is another view of simplicity as a goal of critiques as two modes that focus on changing cultural practice and phenomena. Literary criticism articulates and examines particular cultural norms; criticism articulates and makes sense of complex cultural phenomena (Ibid: P. 228). Reconstructive critique focuses on existing conditions, and existing institutions. It attempts to understand the conditions or grounds by which criticism speaks for literature.

The active development of New Criticism came to an end in the late 1950s, with the rise of the archetypal criticism associated with the psychologist Carl Jung, which produced a critique of the New Criticism in a practical influence and prestige. 


\section{Significance of Archetypal Criticism}

Archetypal criticism argues that archetypes determine the form and function of literary works, that a text meaning is shaped by cultural and psychological myths. Archetypes are the unknowable basic forms personified or concretized in motifs such as the quest or the heavenly ascent, recognizable character types such as the trickster or the hero, symbols such as the apple or snake, or images such as crucifixion (Biddle, 1989: P. 25).

Archetypal criticism gets its impetus from psychologist Carl Jung, who postulated that human kind has a "collective unconscious", a kind of universal psyche, which is manifested in dreams and myths and which harbors themes and images that we all inherit. Literature, therefore, imitates not the world but rather the "total dream of human kind", Jung called mythology the "textbook of the archetypes" (Walker, 2002: P. 17).

Archetypal critics find New Criticism too atomistic in ignoring intertextual elements and in approaching the text as if it existed in a vacuum. After all, we recognize story patterns and symbolic associations at least from other texts we have read, if not innately; we know to form assumptions and expectations from encounters with black hats, springtime settings, evil step mothers, and so forth. So, surely meaning cannot exist solely on the stage of a work, nor can that work be treated as an independent entity.

Archetypal images and story patterns encourages readers and viewers of films and advertisements to participate ritualistically in basic beliefs, fears, and anxieties of their image. These archetypal features not only constitute the intelligibility of the text, but also tap into a level of desires and anxieties of human kind.

Archetypal literary criticism is a type of critical theory that interprets a text by focusing on recurring myths and archetypes in the narrative, symbols, images, and character types in literary work (Abrams, 1993: PP. 12-14).

\section{Archetype with Examples}

An archetype is a reoccurring symbol or motif throughout literature that represents universal patterns of human nature. The word archetype comes from a compound Greek word for "origin" and "model". There is no single character which is the archetype for all heroes that came after. Almost all works of literature contain examples of archetypical myths that are universal. The plot of a character is found in oral storytelling traditions

and works of literature. Thus, plot is an archetype. ${ }^{(1)}$ Examples of archetype:

So then, royal son of Laertes, Odysseus,

man of exploits, still eager to leave at once

and hurry back to your own home, your

beloved native land? Good luck to you,

even so. Farewell! But if you only knew, 
down deep, what pains are fated to fill

your cup before your reach that shore, you

've stayed right here, preside in our house

With me and be immortal.

(The Odysseus by Homer)

(The Source: Sparknotes.com, 2017)

Calypso foreshadows the difficulties that are presented in this archetypal plot.

Chorus: Two households, both alike in dignity,

In fair Verona, where we lay our scene,

From ancient grudge break to new muting,

Where civil blood makes civil hands unclean.

${ }^{(1)}$ An archetype is a reference to a concept, a person or an object that has served as a prototype of its kind and is the original idea that has come to be used over and over again. Archetypes are literary devices that employ the use of a famous concept, person or object to convey a wealth of meaning. Archetypes are immediately identifiable and even though they run the risk of being overused, they are still the best examples of their kind. See also: http://literary-devices.com/content/archetype. (C) 2010 Literary-Devices

From forth the fatal loins of these two foes

A pair of star-crossed lovers take their life;

Whose misadventur'd piteous overthrows

Doth with their death bury their parents' strife.

(Romeo and Juliet by William Shakespeare)

(The Source: Sparknotes.com, 2017)

The play falls into the tradition of tragic romances and was based on a very similar sixteenth century Italian story.

I don't give a damn, except that I get

bored sometimes

When people tell me to act my

age. Sometimes I act a lot older 


$$
\begin{aligned}
& \text { than I am - I really do - but } \\
& \text { people never notice it. } \\
& \text { people never notice anything. }
\end{aligned}
$$

(The Catcher in the Rye by J. D. Salinger)

(The Source: www.Goodreads.com, 2017)

Rebel characters often criticize problems in culture. Some rebels attempt to change the culture, while others just reject it.

The concept of an archetype appears in areas relating to behaviour, modern psychological theory, and literary analysis. Usage of archetypes in specific pieces of writing is a holistic approach. Archetypes have a standard and recurring depiction in a particular human culture and the whole human race that ultimately lays concrete pillars and can shape the whole structure in a literary work. Archetypal literary criticism argues that archetypes determine the form and function of literary works and that text meaning is shaped by cultural and psychological myths. Cultural archetypes are the unknowable basic forms personified or made concrete by recurring images, symbols, or patterns. The archetypes reveal shared roles among universal societies, such as the role of the mother in her natural relations with all members of the family. This archetype may create a shared imagery which is defined by many stereotypes that have not separated themselves from the traditional, biological, religious, and mythical framework.

The significance of myth is to show the relationship between archetypes and archetypal patterns that may be reflected in legend, folklore, and ideology with reference to the cultural environments in which they grow (Philip, 1962: P. 149).

Archetypes are universal symbols, as Philip Wheelwright (1962: P. 111), explains in Metaphor and Reality, such as symbols are:

$$
\begin{aligned}
& \text { Those which carry the same or very similar } \\
& \text { meanings for a large portion, if not all, } \\
& \text { of mankind. It is a discoverable fact that } \\
& \text { certain symbols. Such as the sky father and } \\
& \text { earth mother. }
\end{aligned}
$$

Creation is perhaps the most fundamental of all archetypal motifs. Virtually every mythology is built on some account of how the cosmos, nature, and humankind were brought into existence some supernatural beings. Immortality is another fundamental archetype, generally taking one of two basic narrative forms:

A. Escape from time: "Return to Paradise."

B. Mystical submersion into cyclical time: "The Themes of Endless Death and Regeneration." 
C. The quest: "The Hero": "Savior Undertakers our Long Journey during which he or she must Perform Impossible Tasks."

D. Initiation: "The Hero Undertakes a Series of Excruciating Ordeals in Passing from Ignorance and Immaturity to Social and Spiritual Adulthood."

E. The Sacrificial Scapegoat: "The hero": with whom the Welfare of the Tribe or Nation is Identified." (Wilfred, 1992: P. 154).

Archetypes may be found in even more complex combinations as genres or types of literature that conform with the major phases of the seasonal cycle. Northrop Frye, 1957), indicates the correspondent genres for the four seasons as follows:

1. The mythos of spring: Comedy.

2. The mythos of summer: Romance.

3. The mythos of fall: Tragedy.

4. The mythos of winter: Irony.

\section{Literary Criticism Usage}

Literary criticism is not an abstract, intellectual exercise; it is a natural response to literature. It is nothing more than discourse-spoken or written-about literature. Formalist criticism regards literature as a unique form of human knowledge that needs to be examined on its own terms, e.g. "The Solitary Reaper"; but biographical criticism begins with the simple but central insight of literature is written by actual people and that understanding author's life can help readers more thoroughly comprehend the work, e.g., "A Portrait of the Artists as a Young Man"; "A Biological Study of David Copperfield"; and Historical Criticism seeks to understand a literary work by investigating the social, and intellectual context that produced it - a context that necessarily include the artist's biography and milieu, e.g., by Hugh Kenner of Ezra Pound's imagistic "In a Station of the Metro."

Literature is opposed to the works of science as it aims at pleasure and aesthetic unity rather than truth. Images chiefly represent the feelings of the author. Great literature is built not only on fancy but also on imagination; relying on the ability to combine images from the world to create extended metaphors and allegories, it also fuses those images into a single image or feeling as the founder of modern theoretical and critical practice is the poet Samuel Taylor Coleridge (1772-1834) established in his principles of literature. Aristotle's chiefly contributions to literary criticism include:

1. A work of art is an imitation of nature that reflects a high form of art in exhibiting noble characters and noble deeds. The act of imitation gives the reader pleasure.

2. Art possesses form: it has a beginning, middle, and an end. A tragedy is thus an organic whole.

3. Tragedy must have an emotional effect on its audience and bring about "catharsis".

4. The universal rather than the particular should be stressed, e.g., history should deal with events.

5. While the poet must pay attention to diction or language itself; it is thought expressed through language that are of the utmost concern (John, 2005). 


\section{Conclusions}

Archetypes are primordial inherent pattern, psychological structures common to all human beings, emerging from the collective unconsciousness and reflected in symbols, images, and themes. Theses changing over time effects, can be expressed in myths, dreams, metaphors and narratives in general. Currently, multidisciplinary approaches claim that the archetypes could be viewed as governing factors in complex and chaotic systems, such as the ones of human behaviour and action (Stefanos, 2006: P. 2).

Pearson (1998), states that "archetypes are psychological structures, reflected in symbols, images, and themes, common to all cultures and all times; we experience them within us as different parts of ourselves, but they can manifest differently from person to person, influenced by its individually, culture, setting and time in history: it means how we see the world, in our own particularview, and how we interpret differently what happens to us." Haule (2004), illustrates that "the archetypes is an empty program requiring cultural content to fill it, each culture has the freedom to find its own way of imagining and enacting the universal pattern." Also, Campbell (1988), mentions that humans reveal their commonalities in their myths, which are the stories of our quest, meaning, and substance. Archetypal transformations model is used as an interior knowledge management system for consultants and facilitators. (Ibid: P. 3).

The study tries to show the significance of human culture in reference to psychological standards that help in showing the complex thoughts that might be affected by emotions, feelings, and passion. People are affected by their society and may be motivated to their paths. Identity is been checked as a role and tool to define its meaning and function. We, as human beings, might be unable to encounter our traditions in terms of modes, beliefs, present values, and future hopes and aspirations; so that we can rely on our minds to explore the inner motifs and human nature that are reflected in sorrowfulness, sadness, happiness, and the images of joyfulness. Our attitudes have been determined by common psychological responses. These images are called "Archetypes"; in relation to the universe. In addition to, the cultural practice (norms), needs recreation to be understood in the present development.

Psychology becomes influential in literary criticism particularly in illustrating form, function, and meaning with conscious archetypes to approach texts and contexts that mean isolation of any element causes deformity to basic patterns and might have anxieties to the image or symbol. Therefore, features are interpretive throughout literature by using behaviour, modern psychological theory and literary analysis. Archetype is a device that depicts a particular human culture. Literature tries to amuse people rather than making them busy with facts and truths that might be unbearable. Images reflect the author's feelings that are shown clearly in fancy and imagination.

\section{References}

Abrams, M. H. (1993). Archetypal Criticism: A Glossary of Literary Terms. Fort worth: HBJ.

Biddle, A. W. \& Toby, F. (1989). Reading, Writing, and the Study of Literature. New York, Random House.

Ca mpbell, J. (1998). The Powerful Myth, within Bill Moyers. New York: Doubleday.

Douglas, H. (2013). "Online Etymology Dictionary - Archetype." Brown, R. S. Beyond the Evolutionary Paradigm in Consciousness Studies. The Journal of Transpersonal Psychology, 45.2, 159-171. 
Haule, J. R. (2004). Evolution and Archetype: The Biology of Jung. https://www.LiteraryDevices.net.

Johns, H. (2005). Guide to Literary Criticism, Johns Hopkins University Press.

Lynn, S. (1988). Texts and Contents: Writing about Literature with Critical Theory. $2^{\text {nd }}$ Edit. NY: Longman.

Marinela, L. (1918). English Criticism after the Second World War. Al ba Iulia.

Michael, D. Introduction to Literature: Archetypal Criticism.

Michiotis, S. (2005). The Significance of Archetypes and the Use of Narratives in Knowledge, Change and Society. Virtual Presentation at the Fifth International Conference on Knowledge, Culture and Change in Organizations, July 2005. Technology Transfer and Synthesis.

Pears on, C. (1998). The Hero Within: Six Archetypes we Live by. New York: Harper Collins.

Walker, S. F. (2002). Jung and the Jungians on Myth. NY: Routl edge.

Wilfred, L. G. (1992). Mythological and Archetypal Approaches: A Hand Book of Critical Approaches to Literature. (New York: Oxford University Press).

Wheelwright, P. (1962). Metaphor and Reality. (Bloomington: Indian University Press). 